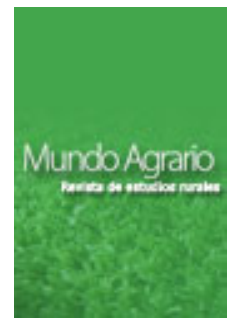

Mundo Agrario vol. 18, no 39, e073, diciembre 2017. ISSN 1515-5994

Universidad Nacional de La Plata.

Facultad de Humanidades y Ciencias de la Educación.

Centro de Historia Argentina y Americana

\title{
La protesta campesina en el Catatumbo Colombia (2013). Un análisis sociopolítico
}

\author{
The peasant protest in the Catatumbo Colombia (2013). A social \\ and political analysis
}

\section{Edwin Cruz Rodríguez *}

* Universidad Nacional de Colombia, Colombial ecruzr@unal.edu.co

\section{Palabras Clave RESUMEN}

Colombia Este artículo analiza el paro campesino en el Catatumbo (Colombia) en 2013. Adopta el enfoque de los procesos políticos para responder cuáles fueron sus determinantes. Frente a los altos niveles de represión y criminalización,

Paro campesino el campesinado respondió con un proceso organizativo que le permitió capitalizar ciertas oportunidades políticas,

Catatumbo construir un marco de acción colectiva basado en la reivindicación de una Zona de Reserva Campesina y establecer alianzas con diversos actores sociales y políticos. Sin embargo, esto no fue suficiente para cambiar la política del Estado central frente a la región, pues los compromisos que éste adquirió siguen sin materializarse.

Acción colectiva

Trabajo

\section{KEYWORDS}

Colombia

Peasant strike

Catatumbo

Collective action

\section{ABSTRACT}

This paper studies the peasant strike in the Catatumbo (Colombia) in 2013. In order to answer what were the determinants goes to approach political processes. Faced with high levels of repression and criminalization, the peasants responded with an organizational process that allowed him to capitalize certain political opportunities, build a framework for collective action based on the claim of Campesino Reserve Zone and establish alliances with various social and political actors. However, this was not enough to change the policy of the central government to the region, since it, acquired commitments still do not materialize. 


\section{Introducción}

En junio y julio de 2013 la región del Catatumbo, al nororiente de Colombia, fue agitada durante 53 días por un paro campesino que movilizó más de diez mil personas y mantuvo bloqueada buena parte del país. El desencadenante de la protesta fue la erradicación forzada de cultivos de uso ilícito, a cargo de las Fuerzas Armadas (FF.AA.), sin implementar programas de economía alternativa. Sin embargo, en la protesta confluyen problemas estructurales que han afectado a esta región estratégica sistemáticamente abandonada por el Estado, ubicada en la frontera con Venezuela y rica en recursos naturales cuya explotación ha producido varios ciclos de violencia.

Los pobladores originarios de la región fueron los pueblos Motilón Barí, diezmados desde la Colonia y combatidos por las empresas petroleras estadounidenses, que llegaron a la región en los años treinta tras apoderarse de la Concesión Barco, vigente entre 1905 y 1975, a partir de argucias jurídicas, presiones diplomáticas y la complicidad de testaferros nacionales. La explotación petrolera impulsó la colonización de la región, pero esta no recibió prácticamente ningún beneficio debido a las desiguales condiciones establecidas en los contratos; por el contrario, el enclave petrolero produjo diversos problemas sociales y un deterioro irremediable del medio ambiente natural (Vega y Aguilera, 1995).

A principios de los setenta, el Ejército de Liberación Nacional (ELN) encontró en la industria del petróleo una forma de financiamiento y legitimación de su accionar mediante un discurso nacionalista. En 1982 llegaron las Fuerzas Armadas Revolucionarias de Colombia (FARC), con el objetivo de controlar la cordillera oriental; posteriormente encontrarían apoyo entre los cultivadores y recolectores de hoja de coca. En la región también hace presencia una disidencia del Ejército de Liberación Popular (EPL), que se rehusó a desmovilizarse en 1991 y que tiene un vínculo marcado con el narcotráfico (FIP, 2013).

La propagación de los cultivos de coca en los años ochenta, debido a las fumigaciones en el sur del país, agregó otro factor de violencia a la región (PNUD, 2014, pp. 10-11). Entre 1998 y 2005 el paramilitarismo hizo presencia con el Bloque Catatumbo de las Autodefensas Unidas de Colombia (AUC), que en ese período asesinó cerca de 11.200 personas, desplazó 19.000 familias, realizó 60 masacres y dejó 600 personas desaparecidas. La masacre más sanguinaria fue la de La Gabarra, el 21 de agosto de 1999, con un saldo de 49 personas muertas y 112 desaparecidas.

La guerra destrozó el tejido social y cualquier forma de organización del campesinado, llevó a un desplazamiento de 77.495 personas y transformó la estructura de la propiedad y los usos del suelo, generando grandes concentraciones ganaderas y de palma africana, de la mano del programa Plante y las "alianzas productivas" con grandes empresarios agroindustriales promovidas por el gobierno de Pastrana en el período 1998-2002 (Molano, 2013, pp. 46-47; PNUD, 2014, p. 18). Desde 2003, el Bloque Catatumbo inició un proceso de desmovilización y la región fue militarizada bajo las directrices de la política de seguridad democrática. La agudización de las confrontaciones sumió a la región en una crisis humanitaria y motivó desplazamientos masivos. Al mismo tiempo, se dispararon los proyectos de explotación de minerales como el carbón, el oro y el petróleo.

Lo anterior configura al Catatumbo como una región de alto riesgo para la protesta (Peñaranda, 2011). En este contexto, una movilización intensa y prolongada es prácticamente excepcional. Este artículo examina el paro de 2013 con el fin de explicar cuáles fueron sus determinantes, apoyado en el enfoque de los procesos políticos para el análisis de los movimientos sociales (McAdam y Zald, 1999; Tarrow, 1997;; Tilly, McAdam y Tarrow, 2005). Esta protesta fue posible porque, frente a los altos niveles de represión y criminalización, el campesinado del Catatumbo respondió con un proceso organizativo que le permitió capitalizar oportunidades políticas, construir un marco de acción colectiva basado en la reivindicación de una Zona de Reserva Campesina (ZRC) que da sentido a la lucha en el largo plazo, y establecer alianzas con diversos actores sociales y políticos que la respaldaron. Sin embargo, esto no fue suficiente para cambiar la política del Estado central frente a la región, pues los compromisos que éste adquirió siguen sin materializarse.

Para desarrollar este argumento, en primer lugar, se reconstruye la contienda política en el marco de la cual se 
produjo la protesta. En la segunda parte se examinan la estructura de oportunidades políticas, las estructuras de movilización y los marcos de acción colectiva.

\section{La contienda política}

La categoría de contienda política captura la fluctuación de la política en contextos institucionales (política contenida) y no institucionales (política disruptiva). Es definida como "la interacción episódica, pública y colectiva entre los reivindicadores y sus objetos cuando: (a) al menos un gobierno es uno de los reivindicadores y (b) las reivindicaciones, caso de ser satisfechas, afectarían a los intereses de al menos uno de los reivindicadores” (McAdam, Tarrow y Tilly, 2005, p. 5). La contienda en la que se enmarca el paro del Catatumbo está estructurada por la reivindicación de la ZRC, vista por los manifestantes como una forma de ordenamiento territorial que puede resolver buena parte de los problemas asociados a los usos del suelo, y por el gobierno como una demanda inconveniente, ya que daría ventajas estratégicas a la guerrilla de las FARC.

Esta contienda se desarrolla en tres momentos. En el primero, el gobierno responde con la criminalización y la represión, mientras los manifestantes ganan adeptos. En el segundo, el gobierno oscila entre negociar y proponer un plan alternativo que desconoce el pliego de exigencias de los manifestantes, esperando que la movilización se desgaste. En fin, en el tercer momento la estrategia del gobierno parece rendir sus frutos, pues los manifestantes recurren a una comisión de mediadores y acceden a retirar los bloqueos para negociar.

\subsection{La disputa por la Zona de Reserva Campesina (ZRC)}

Los antecedentes del paro de 2013 se remontan a 2004, cuando se desplegó en municipios como Tibú la operación Fortaleza de las FF.AA., pues la agudización de la guerra sumió a la región en una crisis humanitaria. El campesinado enfrentó la situación mediante un proceso organizativo que condujo a la reivindicación de la ZRC como parte de la solución de la crisis.

La militarización y el inicio de la erradicación forzada de cultivos de uso ilícito, sin alternativas económicas para los cultivadores, llevaron a la región a una situación complicada frente a la cual varias comunidades se asociaron en el "Refugio Humanitario, Comunitario y Temporal del Catatumbo", instalado el 29 de abril de 2009 en la vereda Caño Tomás, corregimiento de Fronteras, municipio de Teorama, departamento de Norte de Santander, bajo el lema "por la vida, la dignidad, la tenencia de la tierra y la permanencia en el territorio". Ese campamento, que se prolongó por cerca de un año y medio, promovió la Mesa de Interlocución y Acuerdo (MIA), un espacio de encuentro con el gobierno, llevada a cabo el 28 y 29 de agosto de 2009 con la participación de las autoridades locales, mil campesinos, 150 juntas de acción comunal, el gobernador de Norte de Santander, el ministro de Agricultura, la Procuraduría y la Defensoría del Pueblo. El gobierno se comprometió a tratar la crisis humanitaria en la región y acompañar la creación de la ZRC (León, 2013).

La figura de las ZRC fue creada por la Ley 160 de 1994, como entidades territoriales en zonas de colonización para estabilizar la economía de los colonos y la frontera agrícola (Suhner, 2002, p. 118). En realidad, las zonas de reserva campesina hunden sus raíces en el proceso de colonización-expulsión violenta que ha caracterizado a la historia del país, y está en la raíz del conflicto armado: los campesinos vuelven productivas las tierras allende la frontera agrícola, pero seguidamente son expulsados de forma violenta o con argucias legales por parte de terratenientes, viéndose obligados a recomenzar la colonización (Ramírez, 1990, pp. 57-71). Las ZRC se proponen evitar la concentración de la tierra y fomentar la pequeña propiedad campesina, pero no es una medida que ataque estructuralmente el problema, simplemente concede baldíos a los campesinos sin afectar la gran propiedad. De hecho, en la misma ley se preveían Zonas de Desarrollo Empresarial, para la explotación de baldíos distintos a las ZRC (Estrada, 2013, pp. 24-25).

El Decreto 1777 de 1996 reglamentó la figura, en buena medida debido a las marchas campesinas de ese año (Suhner, 2002, p. 119). Con este marco jurídico y un préstamo del Banco Mundial, desde 1998 comenzó un 
proyecto piloto, de tal manera que entre 1997 y 2002 se reconocieron seis ZRC en el Pato-Balsillas (Caquetá), Bajo Cuembí y Comandante (Puerto Asis-Putumayo), Calamar (Guaviare), Cabrera (Cundinamarca), Arenal y Morales (Sur de Bolívar) y Valle del Río Cimitarra (Nordeste antioqueño y Sur de Bolívar) (PNUD, 2012, p. 206). No obstante, a partir de 2002 las ZRC fueron estigmatizadas por la política de seguridad democrática del gobierno de Uribe (2002-2010), que las concibió como retaguardia estratégica de la guerrilla y vetó la creación de ZRC. Este veto operaría en la coyuntura de 2013, porque el primer punto acordado entre el gobierno de Santos (20102014) y las FARC en las conversaciones de paz de La Habana sobre política de desarrollo agrario integral, contempla el fomento de esas figuras (Estrada, 2013, p. 29).

Las dificultades de acceso a la tierra, y la negativa a entrar en alianzas productivas que consideran desfavorables con las empresas palmicultoras, motivaron al campesinado del Catatumbo a iniciar el trámite para la declaratoria de la ZRC. Esta comprende partes de los siete municipios de la región (Convención, Teorama, El Tarra, San Calixto, El Carmen, Tibú y Hacarí, en el departamento de Norte de Santander), 326 veredas, dos resguardos indígenas, el Parque Nacional Catatumbo y las zonas de reserva forestal (Salinas, 2013). La MIA desarrolló audiencias populares sobre problemas como la permanencia en el territorio, el respeto por las comunidades indígenas, la suspensión de la aspersión de cultivos de uso ilícito, la erradicación de los factores socioeconómicos que dieron origen a la siembra de la coca, la defensa de los recursos naturales y el cuidado del medio ambiente. En la audiencia del 10 y 11 de marzo de 2011, en El Tarra, se decidió trabajar por la ZRC del Catatumbo como alternativa razonable de uso del territorio, muy distinta de la que fomentan las empresas de palma y petróleo, para superar la crisis humanitaria (“Catatumbo resiste -Tercera Entrega-”, 2013).

En diciembre de 2011, el Instituto Colombiano de Desarrollo Rural (Incoder), firmó un convenio por 350 millones de pesos para estudios técnicos necesarios para delimitar la zona. El 30 de marzo de 2012, los campesinos realizaron en Tibú una asamblea con la subgerente de tierras de esa entidad, Jhenifer Mojica, en la que participaron 1.500 personas. En 2013 el gobierno financió otros estudios por 750 millones de pesos, con el fin de sustraer la zona de reserva forestal del territorio de la ZRC. Sin embargo, pese a surtir todos los trámites, la junta directiva del Incoder nunca accedió a la creación de la ZRC (León, 2013).

Su negativa se explica por el veto de sectores gubernamentales, en especial de las FF.AA., que perciben el proyecto como una iniciativa de las FARC para dominar un territorio estratégico. A principios de 2013, el ministro de Agricultura Juan Camilo Restrepo (2013) llegó a afirmar que no se podía ceder en el Catatumbo lo que no se había cedido en La Habana, y que la guerrilla quería establecer “republiquetas independientes”, remoquete con el que se designaron los caseríos de campesinos comunistas, entre ellos el de Marquetalia (Tolima) que fue bombardeado en 1964, hecho que daría origen a las FARC (Pizarro, 2011). Según León (2013), los altos funcionarios del gobierno ni siquiera sabían de todo el trámite que había tenido la ZRC.

En el momento de la protesta, el gobierno promovía la erradicación manual de cultivos de uso ilícito en el marco del Plan Consolidación, a cargo de las FF.AA. y diseñado sin consultar al campesinado, pero no había cumplido los compromisos adquiridos con los campesinos producto de anteriores protestas (Salinas, 2013). Con o sin diálogos de paz, las demandas del campesinado en Catatumbo vienen de antes y evidencian el histórico descuido estatal con esa región, pues son prácticamente iguales a las que se presentaron desde el paro del nororiente de 1987, y que se reiteraron en 1988, 1995, 1996, 1997, 1998, 1999 y 2010 (Suhner, 2002, p. 40; Restrepo, 2013).

\subsection{Midiendo fuerzas}

La estrategia del gobierno para enfrentar la protesta combinó una dura represión y la negativa a negociar el pliego de exigencias de los campesinos. Sin embargo, la protesta se fortaleció al atraer un número considerable de manifestantes.

Las movilizaciones comenzaron en Tibú la madrugada del 11 de junio, con bloqueos en la vía que de ese municipio conduce a Cúcuta, la capital del departamento. El campesinado demandaba suspender la erradicación 
de cultivos ilícitos, concertar una política de sustitución en el marco de la ZRC y reconocer esta figura territorial (“300 campesinos”, 2013). Al día siguiente había cerca de 3000 campesinos en la protesta (“Tensión en el Catatumbo”, 2013). Simultáneamente empezó una campaña de criminalización, especialmente por parte del ministerio de Defensa y los militares, que vincularon las demandas del campesinado con los intereses de las FARC.

El mismo día en la tarde, una turba se tomó la sede de la Fiscalía en Tibú e incineró los archivos. La Asociación Campesina del Catatumbo (Ascamcat), que lideró la protesta, negó que los manifestantes en el sitio La Cuarta, a cuatro kilómetros del casco urbano, tuviesen algo que ver con esos hechos. El alcalde de Tibú, Gustavo León, los respaldó. La Policía también responsabilizó a grupos al margen de la ley de quemar los archivos de la Fiscalía. Sin embargo, el 13 de junio se decretó toque de queda en Tibú, el comercio y las actividades educativas fueron paralizadas y la región fue militarizada (“Ascamcat aseguró”, 2013).

Los bloqueos en la vía Tibú-Cúcuta afectaban la producción de palma de aceite, las entradas a la refinería de la Empresa Colombiana de Petróleos (Ecopetrol), e incomunicaban a Colombia con Venezuela. Los más fuertes eran los de Campo 2 y La Cuatro, donde se concentraban 2000 campesinos. Había otros puntos de bloqueo en las vías Ocaña-Aguachica y Ocaña-Convención en el sitio La Ye (“1.200 campesinos”, 2013). El sábado 15 de junio ya se empezaba a hablar del desabastecimiento de víveres en la región y se produjeron enfrentamientos entre la fuerza pública -el Escuadrón Móvil Antidisturbios (Esmad), la policía antinarcóticos y el Ejército- y los campesinos por más de 7 horas ("Reportaje”, 2013). El gobernador de Norte de Santander, Edgar Díaz, se mostró a favor de suspender la fumigación de cultivos de uso ilícito mientras se encontraba alguna alternativa, el gobierno puso a la cabeza de las negociaciones al nuevo ministro de Agricultura, Francisco Estupiñán (“1.200 campesinos”, 2013).

Los manifestantes convocaron una primera negociación en el marco de la MIA el 19 de junio en Tibú. Participarían los ministros de Agricultura, Interior, Minas, Defensa y Ambiente, el gobernador de Norte de Santander, el gerente del Incoder, la Defensoría del Pueblo, representantes de la Iglesia y los alcaldes de los 7 municipios del Catatumbo (“Catatumbo resiste -Segunda entrega-”, 2013). Por parte del campesinado participaría una Asamblea Permanente de Campesinos, compuesta por 200 líderes, pero también habría seis voceros: José del Carmen Abril, Elizabeth Pabón, Eugenio Guerrero, Juan Carlos Quintero, César Jeréz y Gilma Tellez, además de un grupo de asesores (Ascamcat, 2013a). A esa fecha había más de 7000 campesinos en la movilización ("Marchas en el Catatumbo", 2013). El gobierno pedía la presencia de 10 representantes campesinos, de 4800 agremiados, pero finalmente aceptó la propuesta de los campesinos. Se discutiría el reconocimiento de la ZRC, la suspensión de la erradicación de cultivos de coca y su sustitución por una propuesta alternativa, y un subsidio de 1,5 millones de pesos mensuales para las familias afectadas durante dos años. Al mismo tiempo que se iba a desarrollar la reunión, en La Ye la Policía reprimía otra marcha (“Tibú”, 2013).

Para los campesinos resultó inadmisible la asistencia a la MIA, por exigencia del ministro de Agricultura, del director de seguridad ciudadana de la Policía, general Rodolfo Palomino, y del comandante de la Fuerza Vulcano del Ejército, general Marcolino Tamayo. Consideraban que no había razones para que los militares, que no habían tenido presencia en la MIA desde 2009, y que además habían criminalizado el movimiento al ligarlo con las FARC, estuvieran presentes. Por eso, abandonaron la reunión. El ministro Estupiñán se quedó dialogando con cerca de 20 campesinos, y alrededor de las 4 p.m. anunció que habían acordado crear una mesa de trabajo con alcaldes y gobernadores, para desarrollar un programa de inversión con un fondo inicial de 3000 millones de pesos en ayudas para los lugares en donde se habían erradicado cultivos de uso ilícito ("Los campesinos de Tibú”, 2013).

Tras el frustrado encuentro, el gobierno empezó a condicionar la negociación al cese de las "vías de hecho”, en palabras del ministro del Interior, Fernando Carrillo. Los manifestantes, por su parte, se negaban a levantar las protestas antes de conseguir los acuerdos. La represión continuó y el 23 de junio murieron dos personas en enfrentamientos entre manifestantes y el Ejército, cuando los primeros querían tomarse el aeropuerto de Ocaña. A estas alturas se calculaba en 14.000 los campesinos en protesta, 10.000 en Ocaña y 4000 en Tibú ("La condición 
del Gobierno”, 2013). El 25 de junio murieron otros dos campesinos y hubo tres heridos por disparos de bala provenientes de la fuerza pública en el sitio La Ye (“Dos campesinos mueren”, 2013).

\subsection{El forcejeo por la negociación}

Al prolongarse la protesta, el gobierno empezó a ser presionado para negociar. El 25 de junio la Federación Nacional de Cultivadores de Palma de Aceite (Fedepalma) lo conminó a negociar, pues la protesta le estaba generando grandes pérdidas económicas (“En riesgo, cosecha de palma”, 2013). El gobierno apostó al desgaste de la protesta, dilatando la negociación al condicionarla al levantamiento de los bloqueos y proponer en su lugar un plan de inversiones al margen del pliego de exigencias de los campesinos.

El jueves 27 de junio, cuando la protesta completaba 17 días, se reunió la MIA en Tibú. Los campesinos se negaban a levantar los bloqueos como condición para negociar y se inclinaban por tratar todos los temas hasta alcanzar una solución (“Avanza el diálogo”, 2013). Al día siguiente, presentaron un pliego de exigencias que incluía (1) mantener la metodología de la MIA con 200 líderes campesinos y seis voceros; (2) la discusión se agruparía en cuatro mesas que se abordarían conforme se fueran alcanzando los acuerdos en su orden: en la primera se trataría la declaratoria de la ZRC, en la segunda la suspensión de la erradicación forzada, un subsidio de 1,5 millones de pesos mensuales por dos años para las familias víctimas de la erradicación y la suspensión del Plan de Consolidación, en la tercera la suspensión de proyectos minero energéticos en la ZRC y la consulta previa a las comunidades campesinas, y en la cuarta los derechos humanos y la represión. También propusieron una caravana humanitaria apoyada por la ONU para mitigar el desabastecimiento de víveres ("Propuesta metodológica”, 2013).

Por su parte, el gobierno propuso un plan de inversiones cercano a los 120.000 millones de pesos, que comprendía un plan de desarrollo alternativo, obras infraestructurales y garantías de protección, entre otras cosas (“Campesinos del Catatumbo analizan plan”, 2013). Empero, para los campesinos era imperativo que se respetaran los trámites adelantados y se reconociera la ZRC. Por eso no aceptaron el plan y se negaron a levantar los bloqueos (“Sigue el paro en el Catatumbo", 2013). En un comunicado, Ascamcat afirmó que luego de anunciar el proyecto los delegados del gobierno se levantaron de la MIA, sin asumir la metodología ni discutir su pliego de exigencias. En su perspectiva, el anuncio de ese plan, que se hizo sin llegar a ningún acuerdo y por fuera de la Mesa, constituía una “cortina de humo” para desmovilizar al campesinado (Ascamcat, 2013b).

El fin de semana los voceros del movimiento se reunieron con los miembros de la comisión facilitadora, formada por los congresistas Iván Cepeda, Gloria Inés Ramírez, Ángela Robledo y Hernando Hernández, en Ocaña. Ante la invitación del presidente Santos para dialogar en Bogotá, Ascamcat decide realizar un gesto de buena voluntad, levantar el bloqueo en Ocaña y hacer unas propuestas específicas: el nombramiento de un moderador imparcial para ordenar la discusión que debería llevarse a cabo con propuestas escritas, el equipo del gobierno debía ser fijo, mantener el acuerdo metodológico (abordaje de los 10 temas del pliego en 4 mesas consecutivas), el borrador de los acuerdos que se fueran alcanzando debía consultarse con los 200 líderes campesinos delegados a la MIA y, para finalizar, solicitaban al gobierno, como gesto de buena voluntad, acordar los subsidios para las familias víctimas de la erradicación forzada de cultivos de coca (“Mensaje de buena voluntad”, 2013).

Sin embargo, el Presidente no los atendió y las negociaciones se encallaron en el problema de la ZRC. Los campesinos argumentaban que la dilación para el reconocimiento se debía al veto del ministerio de Defensa y a los intereses de los agronegocios y las empresas minero-energéticas. Propusieron un referendo para consultar al pueblo indígena Motilón Barí, que se asienta en un resguardo comprendido en el plan de la ZRC, pero el gobierno no aceptó. Como alternativa, nuevamente propuso un plan de desarrollo con un alto componente de obras de infraestructura que serían desarrolladas por el Ejército, lo que en la perspectiva de los campesinos implicaba dar continuidad al Plan de Consolidación (“Lo que se juega en el Catatumbo”, 2013).

Unos días después, el 2 de julio, Ascamcat hizo un llamado a la movilización. Afirmaba que el gobierno no había 
correspondido a la buena voluntad del campesinado, aunque suspendió el bloqueo en Ocaña, y no había voluntad para resolver la crisis del Catatumbo (Ascamcat, 2013c). Los funcionarios del gobierno declararon públicamente que las negociaciones se realizarían en Bogotá, lo que llevó a un pronunciamiento de los voceros campesinos para desmentirlos y aclarar que preferían desarrollar la MIA en Tibú. Además, dado que el Presidente no tuvo tiempo para atenderlos, cuando los convocó a una segunda cita decidieron no asistir. Consideraron que no tenía sentido una reunión sin metodología específica, y que las negociaciones debían tomar en consideración el pliego de exigencias y no el plan del gobierno. También criticaron el hecho de que el gobierno, para concretar esa reunión en Bogotá, no utilizara canales idóneos sino únicamente los medios de comunicación, lo que a su juicio demostraba el desprecio hacia el campesinado (“Expectativa por cita”, 2013).

El jueves 4 de julio, para responder a las noticias que señalaban a los voceros de Ascamcat como miembros de las FARC, fundadas en informes de inteligencia militar, la organización publicó sus perfiles ("Estos son los verdaderos perfiles”, 2013). Al día siguiente, los voceros y dos moderadores del gobierno se reúnen para acordar una metodología de trabajo. La propuesta del gobierno, elaborada con sus altos funcionarios, era iniciar los diálogos el lunes 8 de julio con tres mesas de diálogo y una agenda de negociación de cuatro puntos que se empezaría a discutir una vez se levantara el paro. Los líderes campesinos, por su parte, no aceptan levantar el paro como condición para negociar, manteniendo los bloqueos en la vía Cúcuta-Tibú (“Campesinos del Catatumbo no aceptan propuesta”, 2013).

El 8 de junio, día en que se tenía previsto reiniciar las conversaciones, el gobierno retoma su propuesta de un plan de inversiones y divide en forma unilateral la agenda en dos comisiones de altos funcionarios, una se ocuparía de negociar con los manifestantes mientras la otra se encargaría de evaluar la crisis social ("Gobierno autorizó comisiones”, 2013). Su intención era aislar los problemas que habían provocado una crisis humanitaria en la región, de aquellos más políticos y en su perspectiva ligados a las conversaciones de La Habana, principalmente la declaratoria de la ZRC. Así, el 9 de julio se reinicia el diálogo en Tibú, mientras la otra comisión gubernamental evaluaba la crisis social en Cúcuta. Se abordaron diez puntos, el primero de los cuales fue el reconocimiento de la ZRC. Dado que nuevamente no hubo acuerdo, se decidió no archivarlo sino proseguir con los demás puntos y retomarlo al final (“Negociación en el Catatumbo”, 2013). No obstante, al día siguiente el gobierno nuevamente decidió interrumpir las negociaciones porque los líderes de la protesta se resistían a levantar los bloqueos.

El 12 de julio se presentaron nuevamente enfrentamientos entre los manifestantes y la fuerza pública en Tibú, que dejaron 10 manifestantes y 2 policías heridos (“De nuevo se enfrentan”, 2013). El turno en el equipo negociador del gobierno era para el vicepresidente, Angelino Garzón, quien se desplazaría al día siguiente a la región. Se trataba de un recurso que había jugado el gobierno en anteriores protestas de gran magnitud como el paro camionero en 2011 y el paro cafetero en 2013. El movimiento campesino, por su lado, ampliaba su apoyo. Ese mismo día, en Bogotá, hubo una reunión de delegados de distintas organizaciones campesinas del país, quienes anunciaron un Paro Nacional Agrario en solidaridad con el Catatumbo.

\subsection{La mediación y la suspensión del bloqueo}

El vicepresidente Angelino Garzón vincularía como mediadores a actores relevantes, fundamentales para llegar a un acuerdo y al desbloqueo de las vías. El 13 de julio se reunió con los líderes campesinos e invitó al delegado de la oficina de derechos humanos de la ONU para Colombia, Todd Howland, quien había criticado la represión de la protesta, como mediador (“Vicepresidente Garzón”, 2013).

El gobierno se mostraba dispuesto a negociar la suspensión de la erradicación de cultivos de coca, tras admitir que hubo descoordinación con los programas de economía alternativa, pero no iba a reconocer la ZRC y seguía condicionando el diálogo al levantamiento de los bloqueos. El 15 de julio el Vicepresidente se reunió con los 6 voceros campesinos acompañado de Howland, el alcalde de Tibú y el gobernador de Norte de Santander, por más de 7 horas. Al final, el gobierno ofreció realizar un foro nacional sobre ZRC, los campesinos mantuvieron que no levantarían los bloqueos hasta que se reconociera la ZRC (“Garzón no puso punto final”, 2013). 
El 25 de julio los líderes de Ascamcat pidieron una audiencia a Santos en Cúcuta, aprovechando que el presidente se desplazó a esa ciudad a inaugurar obras. Otra vez plantearon la posibilidad de realizar una distensión del bloqueo. A cambio pedían que el gobierno reiniciara las conversaciones bajo el compromiso de alcanzar un acuerdo en una semana. Al día siguiente, Santos se reunió con el gobernador de Santander, los alcaldes de la región y otros dirigentes en Cúcuta, tras de lo cual reafirmó que no dialogaría con los manifestantes, que ya llevaban 46 días en paro, hasta que levantaran los bloqueos (“Santos mantiene el no al diálogo”, 2013).

El 28 de julio los voceros campesinos Olga Quintero y Andrés Gil recurrieron al sacerdote Jesuita, Francisco de Roux, para que desarrollara una tarea de mediación. De Roux, por su parte, convocó una comisión conformada por el vicepresidente Angelino Garzón, el presidente del Congreso Juan Fernando Cristo, el representante a la Cámara Iván Cepeda, el representante de la ONU en Colombia Todd Howland y el expresidente Ernesto Samper. El 29 de junio los manifestantes retiraron el bloqueo en Campo Dos, uno de los cinco puntos en la vía TibúCúcuta, como gesto de buena voluntad para reiniciar el diálogo y en respuesta a solicitudes del gremio de los arroceros de la zona, y presentaron una propuesta de desbloqueo para que a más tardar el 5 de agosto se retomara el diálogo con el gobierno. Al conocer la propuesta, el presidente Santos accedió a discutir todos los puntos del pliego de exigencias, incluyendo la creación de la ZRC (“El acuerdo” Semana, 2013f).

El miércoles 31 de julio hubo un principio de acuerdo en el que fue fundamental el acompañamiento de la comisión mediadora formada por De Roux. Al día siguiente, se levantarían los bloqueos, el viernes 2 de agosto se haría un "encuentro social por el Catatumbo" para que el Estado atendiera los problemas sociales de la región y el lunes 5 de agosto se daría inicio a la discusión sobre los puntos del pliego de exigencias de los manifestantes (“Logran acuerdo”, 2013). El fiscal general, Eduardo Montealegre, declaró que no habría judicializaciones por participar en las protestas (“Acuerdo social”, 2013).

En la madrugada del 3 de agosto finalmente se produce el levantamiento de los bloqueos. El representante en Colombia de la oficina de derechos humanos de la ONU, Todd Howland, haría la veeduría del proceso de negociaciones (“Campesinos abandonan vías”, 2013). El 9 de agosto se alcanza finalmente un acuerdo entre Ascamcat y el gobierno Santos, según el cual la MIA se reuniría tres días a la semana durante cuatro semanas. La agenda abordaría en forma extensiva los puntos del pliego de exigencias y los problemas de la región, y la Mesa sería instalada el 10 de agosto. Un mes después de iniciadas las negociaciones, persistían los problemas de cumplimiento de los acuerdos y de voluntad por parte de los funcionarios para destinar los recursos necesarios para los programas que permitirían solventar la emergencia social en la región, así como la oposición desde el ministerio de Defensa y los comandantes de la fuerza pública al reconocimiento de la ZRC (Duque, 2013).

En definitiva, la protesta se mantuvo por casi dos meses y consiguió ubicar la problemática de la región en la agenda pública nacional. Sin embargo, su principal objetivo, que se cumpliera el trámite de la ZRC, no se consiguió. Al final la estrategia del gobierno tuvo éxito, pues obligó a los campesinos a suspender la protesta para proceder a una negociación cuyos acuerdos serían nuevamente incumplidos.

\section{Explicando la acción colectiva}

La teoría de los procesos políticos es una síntesis de distintos factores explicativos de la acción colectiva. Sus tres categorías básicas: estructuras de oportunidad política, estructuras de movilización y marcos de acción colectiva, comprenden la dimensión estructural y los elementos subjetivos que están en el origen y desarrollo de toda acción colectiva. El paro en el Catatumbo se produce en un contexto de ascenso de la movilización social, debido a las oportunidades abiertas en el primer gobierno de Santos (2010-2014), en particular su estilo moderado en comparación con el anterior gobierno y la apertura de negociaciones de paz. Sin embargo, la protesta fue duramente criminalizada y reprimida, de forma que su prolongación se explica por el desempeño de sus estructuras de movilización, en particular Ascamcat, y por la capacidad de sus marcos de acción colectiva para articular diversos actores a su causa. 


\subsection{Oportunidades políticas}

La estructura de oportunidad política comprende aquellos elementos del contexto político que incentivan o desincentivan la acción colectiva, los cuales funcionan como variables independientes para explicar su origen y desarrollo (McAdam, McCarthy y Zald, 1999, p. 23). McAdam (1999) ha sugerido que los principales elementos que definen oportunidades políticas son el grado de apertura del sistema político, la estabilidad o inestabilidad de las coaliciones, la disposición de aliados entre las élites políticas para los manifestantes y el nivel de represión estatal.

El paro en el Catatumbo se sitúa en un contexto de ascenso de las protestas sociales en Colombia durante el primer gobierno de Juan Manuel Santos (2010-2014). De acuerdo con el CINEP (2014), en 2013 se presentaron 1027 protestas, cifra superior al número de protestas que se presentaron anualmente desde 1975. El auge de la protesta no sólo se evidencia en las cifras, sino también en las grandes movilizaciones que precedieron el paro en el Catatumbo, como el paro universitario, en octubre de 2011, y el paro nacional cafetero, en febrero y marzo de 2013 (Cruz, 2012, 2013). Este ciclo de protestas fue posible en buena medida por una estructura de oportunidades políticas en la que confluyeron dos procesos: primero, la relativa apertura del gobierno Santos en comparación con el de Uribe (2002-2010) en relación con el tratamiento de la protesta, al que se adiciona el antagonismo entre las élites políticas representadas por cada uno de ellos; y segundo, la ampliación de la agenda pública como consecuencia de las conversaciones de paz entre el gobierno y las FARC en La Habana, que comenzaron en octubre de 2012 y que incentivan al posicionamiento de demandas no tramitadas por parte de distintos actores sociales (Cruz, 2014).

Sin embargo, la respuesta del gobierno frente a la protesta fue la criminalización y la represión. Funcionarios civiles y militares en distintos momentos afirmaron que la protesta estaba manipulada por las FARC para forzar el reconocimiento de la ZRC. Se trata de una representación de la región del Catatumbo y del campesinado muy similar a la que tiene el Estado central de regiones de colonización como la Amazonía, que desplegó frente a las marchas cocaleras de 1996, como lugares vacíos, bárbaros, y una representación de las acciones colectivas como orquestadas por la guerrilla y el narcotráfico (Ramírez, 2001, p. 106). El 13 de junio, el general Marcolino Tamayo, comandante de la Fuerza de Tarea Vulcano, refiriéndose a Ascamcat relacionó las movilizaciones con una supuesta infiltración del terrorismo (“De nuevo se enfrentan”, 2013). El 19 de junio, luego de la frustrada MIA, el mismo presidente Santos afirmó que las marchas estaban infiltradas por las FARC ("Marchas en el Catatumbo", 2013). Un tiempo después, el comandante de las FF.MM., Alejandro Navas, sostuvo que tenía información sobre el interés de las FARC en declarar la ZRC en el Catatumbo ("Lo que se juega en el Catatumbo”, 2013). El 7 de julio el ministro del interior Fernando Carrillo, insinuó que las FARC estaban detrás de las movilizaciones en el Catatumbo para influir en la Mesa de La Habana (“'Quieren incendiar el país’”, 2013).

En tales declaraciones se evidencia un sesgo paternalista sobre los campesinos, que supone que no pueden movilizarse por su propia cuenta sino que lo hacen solamente utilizados u obligados por actores externos como la guerrilla (Ramírez, 2001, p. 115). En algún momento se llegó a cuestionar si César Jeréz, vocero de Ascamcat, era campesino, bajo la premisa de que un campesino no podría haber estudiado en la universidad ni tener posgrados en el exterior. El 4 de julio se publicó información de inteligencia militar según la cual Jeréz era miembro del Partido Comunista Clandestino, dependiente de las FARC, sustentada en que aparecía en el computador del abatido comandante "Raúl Reyes” y en que había estudiado en la Unión Soviética (“Un geólogo estudiado en Europa”, 2013).

Los dirigentes campesinos rechazaron enfáticamente esas acusaciones. Olga Quintero, vocera de Ascamcat, interrogada por la relación entre las conversaciones de La Habana y la protesta del Catatumbo afirmó:

Una cosa es lo que haga las Farc y otra cosa es lo que a los campesinos nos motiva y nos obliga a movilizarnos. Claro que estamos infiltrados pero por la falta de atención del gobierno, estamos “traspasados” pero por la falta de vías, la falta de vías para poder cultivar comida. De eso sí estamos infiltrados. 
(...) Se ha dicho que estamos infiltrados. La policía si se infiltró. Hay fotografías de policías de civil, en las fotos se ven los escudos de la policía, estaban disparando. Esa guerra sucia nos costó la muerte de cuatro campesinos: uno que vendía pollos, otro padre de familia, gente del pueblo, campesinos jóvenes. Yo me hago la siguiente pregunta: si la guerrilla tiene 16 mil personas en la protesta, entonces tienen un poder muy berraco. El gobierno se contradice porque dice que la guerrilla está derrotada pero ve guerrilla por donde quiera que vaya (León, 2013).

El 22 de julio, el Bloque Magdalena Medio de las FARC manifestó su apoyo a la protesta campesina. El ministro de Defensa, Juan Carlos Pinzón, dijo que era una evidencia más de que las FARC estaban detrás de las manifestaciones, pese a que inmediatamente los líderes campesinos rechazaron enfáticamente el supuesto apoyo de la guerrilla ("Manifestantes del Catatumbo solicitan”, 2013). Sin embargo, eso no fue suficiente para que terminara la criminalización. El 30 de julio, en la plenaria del Senado el ministro Pinzón sostuvo que en las protestas había guerrilleros de civil generando violencia y agregó:

lo que no está bien es que nos crean tan bobos esos bandidos, de pensar que nos van a montar en la frontera con Venezuela una zona autonómica que está llena de coca, de armas y de explosivos, y que le sirve de retaguardia de los jefes del terrorismo (“'Que no nos crean bobos’”, 2013).

La criminalización de la protesta terminó por legitimar la dura represión sobre los manifestantes. De hecho, las movilizaciones en el Catatumbo marcan un aumento en los niveles de represión en comparación con anteriores protestas desarrolladas durante el gobierno Santos (Cruz, 2015). El 15 de junio, mientras la fuerza pública denunciaba la infiltración de las FARC, los manifestantes rechazaban el excesivo uso de la fuerza. Uno de los manifestantes, declaró: "Vi cómo los policías se robaban televisores, consumían licor en plena refriega y hasta dispararon armas de fuego, no a nuestros hombres, sino al aire, para intimidarnos" ("Reportaje”, 2013). La lideresa Elizabeth Pabón, por su parte, denunciaba: "quema de casas, enseres y alimentación, así como el corte de energía son la respuesta del Estado a nuestras exigencias" ("Tensión en el Catatumbo”, 2013). Varias fuentes revelaron el uso de armas de fuego y la participación del Ejército en la contención de la protesta ("Catatumbo resiste -Segunda Entrega-”, 2013). El 19 de junio, mientras se preparaba la instalación de la MIA, en el sitio La Ye el Esmad reprimía otra marcha. Hasta ese momento 400 manifestantes habían sido detenidos y ese día se produjeron cuatro heridos graves, uno por herida de bala en el estómago y dos con amputaciones en sus manos (“Tibú”, 2013).

Dos días después de que el presidente Santos dijera que las FARC habían infiltrado el paro, hubo dos personas muertas por tiros de fusil: Leonel Jácome, de 20 años, procedente de la vereda Banderas San Calixto, y Edilson Franco Jaimes, de 21 años, de la vereda Caracol. Ese día hubo por lo menos 10 heridos por balas de fusil provenientes de la fuerza pública (“El Ejército asesinó”, 2013). El 20 de junio, en el sitio La Ye también se presentaron agresiones a bala por parte de las Fuerzas Militares en contra de los campesinos que bloqueaban la vía entre Aguachica (Cesar) y Ocaña (“Continúa la movilización en”, 2013). También se denunció el uso inadecuado de las armas de "letalidad reducida” usadas por el Esmad, como los gases lacrimógenos, que eran disparados a quemarropa, el ingreso a viviendas de los habitantes de algunos barrios sin orden judicial acusándolos de terroristas y guerrilleros, los robos de víveres y objetos de los campamentos, entre otros. El 23 de junio hubo otros dos asesinatos, cuando la fuerza pública abrió fuego contra un grupo de campesinos que intentó tomarse el aeropuerto Aguas Claras de Ocaña: Diomar Humberto Angarita, del corregimiento San Pablo, y Hermides Palacios, de la vereda La Tiradera, municipio de Teorama (“Dos campesinos mueren”, 2013).

La represión llegó a tal nivel que el 10 de julio la oficina de la ONU para los derechos humanos en Colombia denunció públicamente el abuso de la fuerza y solicitó investigar los asesinatos de los cuatro campesinos, como consecuencia de disparos de fusil de alta velocidad, que son de dotación de la Fuerza Pública ("ONU pide investigar”, 2013). Los medios caracterizaron el hecho como el más grande desacuerdo entre el gobierno de Santos y ese organismo, pues el ministro Pinzón rechazó las denuncias como señalamientos "temerarios e irresponsables” (“Señalamientos de ONU”, 2013). 
El desarrollo de la protesta fue posible porque la represión se contrarrestó articulando aliados diversos. En el ámbito político institucional, fue importante el apoyo de un grupo de congresistas. El 17 de junio el entonces representante Iván Cepeda envió una carta al ministro de Agricultura, Francisco Estupiñán, solicitando que atendiera la invitación de los cuatro mil campesinos en protesta a reunirse y escuchar sus demandas ("Carta al Ministro de Agricultura”, 2013). El alcalde de Tibú, Gustavo León, adoptó una posición cercana frente a las razones de los campesinos, en particular en relación con la demanda de alternativas económicas frente a la política de erradicación de cultivos de coca. El 22 de junio, el gobernador de Norte de Santander, Édgar Arias, y los alcaldes de los municipios de la región, demandaron que el presidente Santos participara en forma directa en la solución de la crisis ("Se agudiza problema”, 2013). El 28 de junio, las Comisiones de paz del Congreso de la República emitieron un comunicado instando tanto al gobierno como a los campesinos en protesta a entablar el diálogo (“Comunicado de las comisiones de paz", 2013). Incluso personas del alto gobierno encontraron razonables las demandas de los campesinos. El 10 de julio, el vicepresidente Angelino Garzón afirmó que no era justo que con los actores armados se negociaran los problemas agrarios mientras se reprimía a los campesinos, aun cuando criticó los bloqueos (“Negociación en el Catatumbo", 2013). El 25 de julio hubo una reunión entre los representantes a la Cámara, Iván Cepeda y Ángela María Robledo, y la senadora Gloria Inés Ramírez, presidenta de la Comisión de Paz del Congreso, junto con sindicalistas de Irlanda, Reino Unido y Canadá en La Aduana, sitio a las afueras de Tibú, con los manifestantes, para estudiar alternativas al conflicto ("Campesinos del Catatumbo piden”, 2013).

\section{Tabla 1. Apoyos de organizaciones sociales a la protesta en el Catatumbo}

\begin{tabular}{|c|c|}
\hline Fecha & Apoyo \\
\hline 16 de junio & $\begin{array}{l}\text { Comunidades académicas de las universidades Javeriana, Nacional, Externado y Distrital } \\
\text { de Bogotá publican un comunicado de apoyo a los campesinos y rechazan la represión de } \\
\text { la protesta. }\end{array}$ \\
\hline 19 de & $\begin{array}{l}350 \text { presos políticos recluidos en la cárcel de Cúcuta entraron en huelga de hambre en } \\
\text { apoyo a los campesinos del Catatumbo y enviaron un saludo pregrabado a la MIA. }\end{array}$ \\
\hline $20 \mathrm{~d}$ & $\begin{array}{l}\text { La Mesa Amplia Nacional Estudiantil emite un comunicado de solidaridad con la protesta } \\
\text { en el Catatumbo. }\end{array}$ \\
\hline $27 \mathrm{de}$ & $\begin{array}{l}\text { Una comisión humanitaria de la Agencia Internacional para la Paz y la organización } \\
\text { Justicia y Paz se desplaza desde Bogotá a Catatumbo para proveer asistencia profesional en } \\
\text { salud, atención psicosocial y comunicaciones, entre otros. }\end{array}$ \\
\hline $27 \mathrm{de}$ & $\begin{array}{l}\text { Oidhaco-red internacional de } 35 \text { organizaciones defensoras de derechos humanos europeas } \\
\text { publican un comunicado denunciando la represión de la protesta en el Catatumbo. }\end{array}$ \\
\hline $28 \mathrm{~d}$ & $\begin{array}{l}\text { Varias organizaciones defensoras de derechos humanos latinoamericanas manifiestan } \\
\text { mediante un comunicado su apoyo a la protesta campesina en el Catatumbo. }\end{array}$ \\
\hline $28 \mathrm{dt}$ & $\begin{array}{l}\text { La Federación Sindical Mundial se suma a las denuncias y rechazos de la represión en el } \\
\text { Catatumbo. }\end{array}$ \\
\hline $30 \mathrm{de}$ & $\begin{array}{l}\text { La Asociación de Trabajadores Campesinos del Valle del Cauca (Astracva), publicó un } \\
\text { comunicado en solidaridad con la protesta campesina en el Catatumbo, al tiempo que } \\
\text { denunciaba el autoritarismo del gobierno y la represión. }\end{array}$ \\
\hline 3 de & $\begin{array}{l}\text { En la Plaza de Bolívar de Pereira se realizó una manifestación simbólica llamada } \\
\text { "Catatumbo resiste", para apoyar la protesta y recolectar alimentos y ayudas para los } \\
\text { manifestantes. }\end{array}$ \\
\hline 5 de julio & $\begin{array}{l}\text { Organizaciones sociales de Nariño pertenecientes a la Marcha Patriótica manifiestan su } \\
\text { apoyo a la protesta en el Catatumbo. }\end{array}$ \\
\hline 8 de julio & $\begin{array}{l}\text { Integrantes de Marcha Patriótica Arauca y la Mesa de Organizaciones Cívicas y Populares, } \\
\text { realizaron un bloqueo a las vías de acceso al Departamento de Arauca como protesta y en } \\
\text { solidaridad con el campesinado del Catatumbo. }\end{array}$ \\
\hline 20 de julio & $\begin{array}{l}\text { La Coordinación Colombia Europa Estados Unidos, que reúne organizaciones defensoras } \\
\text { de derechos humanos, emitió un comunicado llamando a la solidaridad con la protesta } \\
\text { campesina en el Catatumbo, pues a su juicio había información creíble y que los obligaba a }\end{array}$ \\
\hline
\end{tabular}




\begin{tabular}{|l|l|}
\hline 20 de julio & $\begin{array}{l}\text { estar alertas ante la posibilidad de un desalojo a la fuerza de los manifestantes. } \\
\text { (Asoquimbo), reunida en Gigante (Huila) emitió un comunicado de solidaridad con los } \\
\text { campesinos movilizados en el Catatumbo. }\end{array}$ \\
\hline 27 de julio & $\begin{array}{l}\text { En el parque Águeda Gallardo de Pamplona, la administración general de la Universidad de } \\
\text { Pamplona y la Asociación Sindical de Profesores Universitarios (Aspu), realizaron una } \\
\text { actividad para recolectar ayudas para los campesinos del Catatumbo. }\end{array}$ \\
\hline $\begin{array}{l}\text { Fuentes: Elaboración del autor en base al seguimiento de los portales: prensarural.org, semana.com, } \\
\text { archapatriótica.org, lasillavacía.com, elespectador.com y eltiempo.com, en junio, julio y agosto de 2013. }\end{array}$ \\
\hline
\end{tabular}

Sectores de la Iglesia también manifestaron respaldo a la protesta. El 15 de junio los obispos de Norte de Santander se solidarizaron con los manifestantes (“No se produjo la reunión”, 2013). El 22 de julio, Monseñor Leonardo Gómez Serna, quien se había desempeñado como obispo en la región del Catatumbo, declaró que las demandas del campesinado eran justas y negó que las ZRC fuesen usadas por la insurgencia; para él, el campesinado era independiente y había recuperado la palabra (“Protestas en el Catatumbo son justas”, 2013).

El apoyo de otras organizaciones sociales y defensoras de derechos humanos también fue muy importante, en particular de las organizaciones campesinas que, junto con Ascamcat, forman parte de la Marcha Patriótica y de la Asociación Nacional de Zonas de Reserva Campesina (Anzorc). A partir del seguimiento de los portales web Prensa Rural, Semana, Marcha Patriótica, La Silla Vacía, El Espectador y El Tiempo, la Tabla 1 muestra los apoyos recibidos.

\subsection{Estructuras de movilización}

Toda acción colectiva requiere unas redes de relaciones sociales o estructuras de movilización que la sustenten, entendidas como los canales formales e informales que permiten a los individuos vincularse a una causa colectiva (McAdam, McCarthy y Zald, 1999, p. 25). Dentro de las estructuras de movilización se destacan las organizaciones del movimiento social, que tienen por objetivo promover la movilización. No obstante, no son las únicas organizaciones formales que participan en una movilización, puesto que con ella también se articulan otras agrupaciones y colectivos con fines diversos, como partidos políticos, grupos de interés y ONG, entre otros. Además, la movilización también vincula organizaciones y formas de asociación de la vida cotidiana que no tienen como objetivo la movilización, pero que en una coyuntura determinada pueden formar parte de ella (redes familiares, de amistad, de vecinos, de trabajo, etc.) (McCarthy, 1999, p. 206).

En el paro del Catatumbo la organización del movimiento social es Ascamcat. Se trata de una organización de segundo nivel, cuyas bases son las comunidades veredales y las juntas de acción comunal de la región, asociaciones de juntas, representantes de algunos gremios y de organizaciones juveniles, estudiantiles y de mujeres, así como distintos comités temáticos con presencia en los territorios de cuando menos 30 veredas (Ascamcat, 2012, pp. 288-289). Su origen se remonta a 2004, cuando debido a la operación Fortaleza 2 del Ejército, que comprometió una ofensiva con bombardeos sobre la región, en la vereda El Suspiro, municipio de Tibú, hubo un desplazamiento masivo hacia el corregimiento de San Juancito en donde se sentaron las bases de la organización campesina (Vargas, 2013). Según uno de sus cofundadores y vicepresidente durante el paro, Juan Carlos Quintero Sierra, ese desplazamiento coincidió con la participación de algunos de los habitantes en un foro organizado por la Universidad Nacional de Colombia bajo el título "Por la Vida en el Nororiente Colombiano", en el cual conocieron experiencias de otras organizaciones. Algunos de los fundadores venían de una experiencia similar de organización del campesinado en medio del conflicto armado y en contextos de alto riesgo, por haber pertenecido desde 1998 a la Asociación Campesina del Valle del Río Cimitarra, que consiguió el reconocimiento de una ZRC y ganó el Premio Nacional de Paz en 2010 (“Estos son los verdaderos perfiles”, 2013). La vocera Olga Quintero recordaba: 
Existimos hace siete años. Nacimos después de que los paras dejaron un saldo de 11.200 muertos en cuatro años y más de 100 mil desplazados. Hubo unos 600 desaparecidos. Salen los paramilitares y entra el Ejército con la Operación Fortaleza, generando bombardeos y el desplazamiento de 50 familias. De acuerdo a esta presión, vimos la necesidad de sacar información de la región, de informar que existíamos, que había una problemática, y empezamos a caminar en el 2006. Nos encontramos con el tema de los falsos positivos, 78 falsos positivos en esta región. Con montajes judiciales, la crisis humanitaria de la región, las necesidades de los campesinos. Somos de los que decimos que la tierra nos pertenece. Lo único que estamos pidiendo es un pedacito de tierra donde se nos permita vivir en paz. Desafortunadamente no nos entienden y siempre intentan estigmatizarnos, opacarnos y desconocernos (León, 2013).

Ascamcat desarrolló su Primer Encuentro el 14, 15 y 16 de octubre de 2006, denominado "En medio de la violencia reflorece el Catatumbo", en el Corregimiento de San Pablo, municipio de Teorama ("Exitoso encuentro", 2006). Participaron 300 delegados de 26 comunidades y 16 juntas de acción comunal, además de organizaciones de jóvenes y comités temáticos. Actualmente es una ONG sin ánimo de lucro con el objetivo de promover diversas causas del campesinado en la región. A lo largo de su historia ha desarrollado importantes procesos de reconstrucción del tejido social afectado por la guerra, por ejemplo mediante la formación de líderes y lideresas campesinas.

Ascamcat tiene una Junta Directiva Colectiva, cuyos integrantes proceden de una asamblea en la que participan representantes de las organizaciones que la conforman, la cual está encargada de tomar las más importantes decisiones (Ascamcat, 2012, pp. 289-290). Tiene instancias en todas las zonas del Catatumbo (alta, media, baja), que funcionan con comités sectoriales (educativos, logísticos, de derechos humanos, jóvenes, ambiente, salud, comunicaciones, mujeres, etc.). Ascamcat pertenece a la Asociación Nacional de Zonas de Reserva Campesina (Anzorc), que aglutina 54 procesos de ZRC en el país. También pertenece a la Marcha Patriótica, un conglomerado de cerca de 1000 organizaciones de todos los sectores sociales a nivel nacional que se formó en 2010 .

El paro de 2013 recibió un apoyo amplio de las comunidades urbanas y rurales de la región. Por ejemplo, las juntas de acción comunal de más de 200 veredas, que son la primera autoridad comunitaria en esta región, fueron importantes para la protesta. Así lo manifiesta Olga Quintero:

Desde las veredas nos están abasteciendo. Las juntas de acción comunal nos están haciendo llegar comida, carne, aportes para podernos mantener. En Bogotá y Barrancabermeja están recogiendo donaciones para hacerle llegar a los campesinos. Mañana entra una acción comunitaria, acompañada por ONG de derechos humanos para verificar la situación en Tibú (León, 2013).

En fin, muy importante fue el apoyo de las comunidades y grupos no dedicados al trabajo agrícola que se solidarizaron con la protesta, puesto que la economía de la región depende en buena medida de la producción campesina y, en consecuencia, del desenlace de la contienda. Por ejemplo, Gerson Guerrero, propietario de un hotel, manifestó que apoyaba la protesta aunque su negocio se viera afectado: "Con esto se desabastece el pueblo y el comercio pierde, pero es un sacrificio para buscar salidas que beneficien a la comunidad. Si los campesinos piden es porque lo necesitan, nadie se va a un paro por 'hobby”” (“Reportaje”, 2013).

\subsection{Marcos de acción colectiva}

Los marcos de acción colectiva son "significados compartidos que impulsan a las personas a la acción colectiva" (Tarrow, 1997, p. 57). En otras palabras, son interpretaciones, “esquemas interpretativos” más o menos coherentes de la realidad, creados estratégicamente por los participantes en un movimiento social con el fin de darle sentido a su acción colectiva (Snow y Benford, 1992, p. 137). Su creación, o proceso de enmarcamiento, implica una serie de interacciones conflictivas, tanto entre los miembros de un movimiento social, como entre estos, sus aliados y 
sus adversarios, con el objetivo de disputar las representaciones de la realidad (Zald, 1999, p. 370; Rivas, 1998, p. 27). Un marco de acción colectiva tiene, como mínimo, tres grandes elementos: primero, un diagnóstico del problema que suscita la acción colectiva y de sus responsables o adversarios; segundo, la definición de un "nosotros" o identidad colectiva que unifique a los manifestantes; y tercero, un "deber ser" o respuesta al problema planteado.

Durante el paro del Catatumbo se produjeron distintos documentos, todos los cuales se inspiran en últimas en el Plan de Desarrollo Sostenible para la Constitución de la Zona de Reserva Campesina del Catatumbo (Ascamcat, 2012). Este, como anteriormente se señaló, implicó un proceso participativo con asesoría técnica del Incoder para realizar un diagnóstico y un conjunto de propuestas para resolver las problemáticas socioeconómicas y ambientales de la región mediante dicha forma de ordenamiento territorial. Se trata de un documento de más de 500 páginas, con gran cantidad de datos e informaciones técnicas. Si bien el marco de acción colectiva recoge en general las propuestas allí consignadas, son expresadas de una manera sencilla, a manera de consignas y demandas concretas en otros documentos que se construyeron en medio de la protesta.

El marco dentro del cual se concibió el problema está basado en una interpretación de la situación en términos de “crisis", la cual es vista desde una perspectiva de larga duración y no sólo coyuntural. Un comunicado del 12 de junio justificaba la movilización por:

una crisis que se acrecienta desde hace 70 años por cuenta de la expoliación, saqueo, masacres, violaciones sistemáticas a los derechos humanos y al DIH por parte de empresas multinacionales, los gobiernos de turno en todos sus niveles y por los efectos del escalonamiento del conflicto armado interno, generando una profunda crisis humanitaria que en los últimos meses se ha agudizado de manera dramática (“Tensión en el Catatumbo”, 2013).

El 25 de junio se da a conocer un documento de metodología para desarrollar la MIA, que en gran medida realiza una síntesis del diagnóstico realizado por Ascamcat de los problemas de la región:

Más de 14.000 campesinos se manifiestan en el Catatumbo buscando la solución a una crisis social, económica y humanitaria enmarcada en los siguientes agravantes:

1. En la región se introdujo hace tres meses una agresiva campaña de erradicación forzada de los cultivos de coca que impactó a las familias campesinas y a la economía regional, el gobierno ni propuso ni implementó ninguna alternativa económica a la coca.

2. La implementación de la política petrolera y minero-energética del gobierno en la región representa la descampesinización del Catatumbo, desplazamiento y pérdida de la tierra y el territorio campesino.

3. El paramilitarismo de Estado implementó en la región el agronegocio de la palma aceitera, legalizando con este modelo económico las masacres, las desapariciones y los miles de desplazados.

4. Más de 200 campesinos presos del Catatumbo, víctimas de supuestos delitos de narcotráfico (ley 30) y rebelión configuran un nuevo modelo de represión judicial regional, modelo que criminaliza la posición política y la economía campesina del cultivo de la coca en el Catatumbo.

5. El gobierno lleva a cabo un plan de consolidación militar contrainsurgente bajo el sofisma del desarrollo rural, el plan va en contravía de la iniciativa de la Zona de Reserva Campesina del Catatumbo y en la práctica recrudece las violaciones a los derechos humanos y la victimización del campesinado por parte de la Fuerza de tarea Vulcano en el Catatumbo.

6. El gobierno se niega a declarar la Zona de Reserva Campesina del Catatumbo atendiendo a un veto ilegal heredado del gobierno Uribe, incumpliendo los acuerdos y la ley 160 de 1994 (Ascamcat, 2013a).

Así, parte del problema es coyuntural, pero de fondo está, paradójicamente, el incumplimiento de la ley por parte del Estado. De hecho, la insistencia de los manifestantes en mantener como espacio de negociación la MIA es una 
evidencia de que se trata de los mismos problemas que el gobierno se comprometió a resolver cuando esta se estableció, el 28 y 29 de agosto de 2009, ya que los acuerdos nunca se cumplieron. El 24 de junio, al preguntarle a Juan Carlos Quintero Sierra, vicepresidente de Ascamcat, por las razones de la protesta, este decía:

Son varios motivos, el primero es el abandono histórico que ha tenido el Gobierno con la región del Catatumbo, es una región olvidada que lo único que ha recibido es el saqueo que sus recursos naturales y la guerra. Además, nosotros creemos que se agotaron todos los mecanismos de interlocución, hemos llegado a acuerdos y todos han quedado en el papel. No se ven las inversiones, ni la constitución de la zona de reserva campesina. Por eso decidimos acudir a las acciones de hecho, esto fue una medida que tomamos porque se nos obligó a hacerlo...Hace dos años venimos adelantando el trámite acorde con la Ley 160 para la constitución de las zonas de reserva campesina, cumplimos hace un año y el Gobierno no ha dado ningún tipo de reconocimiento. También pedimos que se suspendan las erradicaciones de cultivos de uso ilícito hasta que campesinos y Gobierno acuerden un plan contundente de sustitución gradual... Nosotros nos hemos enterado es por los medios de comunicación que hay un ataque muy fuerte contra la figura de la zona de reserva, sectores ganaderos como Fedegan y sectores políticos han querido confundir a la opinión pública pero nosotros lo que estamos pidiendo es que cumplan la ley (“Campesinos del Catatumbo", 2013).

Uno de los problemas que más preocupa al campesinado es la disputa violenta por el territorio entre distintos actores armados y el Estado. El mismo Quintero Sierra, resumió su percepción:

La protesta y el fallido diálogo pusieron en evidencia una vieja verdad del Catatumbo. Por esta región han pasado todos los grupos guerrilleros y el Bloque Catatumbo de las autodefensas de Salvatore Mancuso. Hoy, varios frentes de las FARC, columnas del ELN y una disidencia del EPL controlan las partes más inhóspitas y la frontera con Venezuela, donde la coca es el centro de la economía. La violencia ha azotado las comunidades en todas sus formas. Y hoy, después de miles de muertos, el Catatumbo es una ruta clave del tráfico de cocaína hacia Venezuela y Europa y, por eso, una región en disputa entre las FARC y los grupos sucesores de los paramilitares. En medio de todos esos fuegos cruzados, y en algunos casos bajo su influencia, están los campesinos. Pase lo que pase en los próximos días, en los que los bloqueos y las protestas no amenazan con desaparecer, los campesinos lograron una victoria: llamar de nuevo la atención nacional sobre sus necesidades. Una realidad a la que ni el Estado ni el país le pueden seguir dando la espalda (“Reportaje”, 2013).

Para los campesinos las respuestas del Estado, enfocadas en lo que ellos concibieron como "acciones cívicomilitares" en el marco del Plan de Consolidación implementado por las FF.AA., eran erróneas e insuficientes para resolver la crisis de la región. Al respecto afirmaba Olga Quintero:

No estamos de acuerdo con el Plan de Consolidación a través de campañas cívico-militares. Dicen que han invertido 3 mil millones de pesos en consolidación, pero yo no veo qué tantas obras han hecho, salvo el alcantarillado en La Gabarra, que ahora se les inunda más que antes. ¿Que decimos? Esa plata no la debería manejar el Ministerio de Defensa, sino los otros ministerios.... [Las acciones cívico militares han consistido] por ejemplo, en el colegio de La Gabarra, el Ejército hace actividades como jugar fútbol con la población; campeonatos de fútbol con los profesores; son actividades que ponen en riesgo a las comunidades; hacen manicure, pedicure, jornadas odontológicas. Yo no creo que eso le corresponde a las Fuerzas Militares, sino al Estado tener una política de salud (León, 2013).

Además de la crisis humanitaria producto de la agudización del conflicto armado, los problemas de la región comprenden la falta de alternativas económicas para los campesinos, diferentes a las empresas palmeras, la minería a cielo abierto y los cultivos de coca, así como una política social y económica y no solamente represiva para su sustitución. Así lo puso de presente Olga Quintero: 
hay una serie de empresas que están interesadas en extraer carbón a cielo abierto y nuestra vocación es agrícola. La explotación minera solo le ha dejado ganancias a las empresas... la economía campesina y los cultivos de uso ilícito requiere[n] un tratamiento social y económico, generar propuestas alternativas sustitutivas (León, 2013).

El 11 de junio, cuando inició la protesta y hubo enfrentamientos con la fuerza pública, la vocera Elizabeth Pabón decía:

En el Catatumbo hay multinacionales dedicadas al saqueo de nuestros recursos, y son a esas empresas a quienes el Estado defiende... cuando el campesino pide, se le tilda de guerrillero y narcotraficante y por eso se nos ataca como lo han hecho (“Catatumbo resiste (Primera Entrega)”, 2013).

La identidad, el "nosotros" que permitió aglutinar a los manifestantes, estuvo basada en el marcador de “campesino", "pueblo” y "Catatumbo". La identidad de pueblo está orientada a desmentir el discurso gubernamental, cuando sostenía que se trataba de "vándalos" o bien que estaban manipulados por la guerrilla. Es una identidad positiva, explicitada por el vocero Holmer Pérez:

Cuando el pueblo se organiza, cuando reclama sus derechos, el gobierno estigmatiza y trata de ponernos como lo peor... aquí no hay vandalismo, nosotros no hemos quemado casas y eso tiene que quedar muy claro; aquí está el pueblo organizado luchando por lo que por años se nos ha sido negado... se nos han incumplido muchos acuerdos, como la constitución de la Zona de Reserva Campesina, la puesta en marcha de los proyectos productivos y la sustitución progresiva de los cultivos ilícitos ("Catatumbo resiste (Primera Entrega)”, 2013).

Así pues, frente al principal antagonista que es el Estado se erige el campesino, quien en forma similar a lo que ocurrió durante las protestas cocaleras del Putumayo en 1996 (Ramírez, 2001, p. 19), al mismo tiempo interpela y reclama la presencia estatal, en la medida en que es necesaria para su reconocimiento como ciudadano, en un contexto en el que las regiones de colonización son percibidas por el Estado central como zonas "bárbaras”, donde predomina la delincuencia, el narcotráfico y la violencia, frente a las cuales únicamente se debe desplegar la represión. Por eso, dentro de las consignas de las manifestaciones se destacaron "Somos pueblo, somos Catatumbo", lo que resalta simultáneamente una identidad de clase popular y una identidad regional. Pero también “¡Porque los héroes en Colombia sí existen, y son los campesinos que resisten!”, que interpela directamente el imaginario nacional y particularmente el patriotismo que se cimentó con fuerza en la imagen de las FF.AA. -la consigna parafrasea una de sus propagandas-, sobre todo en el gobierno Uribe (2002-2010) (López, 2014), para señalar que hay una parte olvidada en ese imaginario nacional: la del héroe campesino. De esa manera, se presenta una interpelación a un Estado y una nación que ha olvidado y excluido al campesino, pero también la demanda de reconocimiento de su identidad y presencia estatal para resolver sus problemas.

En fin, el nodo articulador del deber ser, aquello que se percibe como parte de la resolución del problema, es la demanda por la declaración de la ZRC. El pliego de peticiones publicado el 15 de junio exigía: que las negociaciones se desarrollaran en el marco de la MIA; la declaración inmediata de la ZRC del Catatumbo conforme a la Ley 160 de 1994 y al Decreto 1777 de 1996; suspender la erradicación de cultivos de coca e implementar programas de sustitución gradual y concertada de acuerdo al Plan de Desarrollo Sostenible desarrollado en forma participativa para la ZRC del Catatumbo; un subsidio de 1,5 millones de pesos para las familias afectadas por la erradicación forzada de cultivos de coca; suspender los proyectos de la "locomotora minera” y el Plan de Consolidación, así como respetar la consulta previa a las comunidades campesinas cuando existan proyectos que puedan afectarlas; el reconocimiento del carácter civil de Ascamcat por parte de los funcionarios civiles y militares del gobierno; e investigaciones judiciales para resolver la crisis de derechos humanos de la región (Ascamcat, 2013d).

La entrevista que la periodista Juanita León le hizo a la dirigente de Ascamcat, Olga Quintero, constituye en gran medida una síntesis de los argumentos que reivindicaron los manifestantes a favor de la ZRC, una forma de ordenamiento territorial que empodera a las comunidades campesinas frente a los intereses económicos, políticos 
y militares externos:

Estamos pidiendo que se declare la Zona de Reserva Campesina de Tibú... [el gobierno dice:] Que el tema no lo va a tratar y que eso está ligado a La Habana. Nosotros decimos que no. Las Zonas de Reserva Campesina no son iniciativa de las FARC. Esto se logró en los años 90 y ahora no se quiere reconocer esa ley. Lo que estamos pidiendo es que se nos reconozca y se nos cumpla la ley...

¿Entonces, la movilización es por la Zona de Reserva Campesina y no por la erradicación de cultivos?

La necesidad es que se declare la Zona de Reserva Campesina y si se aplica el Plan de Desarrollo que hicimos le podemos dar otra vía a los cultivos ilícitos. Le hemos propuesto al gobierno en años anteriores un proyecto de sustitución gradual de cultivos, que se hiciera un experimento por dos años de manera gradual. Era factible.

\section{¿No se hizo el experimento}

El gobierno no aceptó esa propuesta. Nos contestó que para eso estaban las familias guardabosques, las familias en acción, los jóvenes en acción. Pero esas propuestas son asistencialistas. No necesitamos asistencialismo, sino poder producir y no depender de una mensualidad. Necesitamos es poner a sembrar la tierra (León, 2013).

De las respuestas de la lideresa puede inferirse una defensa de las ZRC como propuesta propia del campesinado ajena a las reivindicaciones de las FARC; el hecho de que el Plan de Desarrollo de la ZRC se percibe como una respuesta para problemas como los cultivos ilícitos superior al “asistencialismo” del gobierno; y un énfasis en la independencia del campesinado siempre y cuando tenga acceso a la tierra. Juan Carlos Quintero adicionaba otras razones para respaldar la demanda por la ZRC:

Esto nos garantiza el acceso a nuestra tierra, nosotros llevamos hasta 70 años reclamando títulos propiedad sobre nuestro territorio. Las zonas de reserva conservan el medio ambiente, son una propuesta de paz con justicia social para la región y hacen que la política pública se profundice a través del campesinado. Nosotros hemos dicho que queremos solucionar esta situación, este sería un aporte de nosotros, los campesinos en la búsqueda de la paz (“Campesinos del Catatumbo”, 2013).

\section{Corolario}

Aunque los problemas que suscita el paro en el Catatumbo están enraizados en la compleja historia reciente de la región, tienen lugar en el contexto de ascenso de la movilización social, en gran parte debido a la reconfiguración del contexto político bajo el primer gobierno Santos (2010-2014), particularmente por su moderación en comparación con el anterior gobierno, y el emprendimiento de un proceso de paz. No obstante, debido al carácter estratégico de la región, también se evidenció un incremento en los niveles de represión y el recurso a estrategias de criminalización por parte del gobierno.

En este contexto, un factor clave para comprender la magnitud de la movilización fue el desempeño de Ascamcat, la principal estructura de movilización del campesinado en esta región, puesto que no solamente demostró una gran capacidad de convocatoria a nivel local, sino que agenció marcos de acción colectiva que permitieron la articulación de actores diversos a su causa. Sin la existencia de este proceso organizativo, que se retrotrae a la época más aguda del conflicto armado en la región y que demuestra un alto nivel de resiliencia y de capacidad de organización, una acción colectiva de tales proporciones habría sido imposible, aún bajo la reconfiguración y la apertura de oportunidades políticas en el contexto de las negociaciones de paz.

El desenlace final del proceso, sin embargo, es ambiguo. Por una parte, la organización campesina exhibió su fortaleza y poder de convocatoria en una movilización que se mantuvo por casi dos meses paralizando una gran parte del país. Pero, por otra, ni el repertorio de confrontación ni la capacidad para establecer distintas alianzas y posicionar las problemáticas de la región en la agenda pública nacional consiguieron persuadir al gobierno sobre la necesidad de implementar políticas para resolver sus distintos problemas y, en particular, el reconocimiento de 
una ZRC. Esto muestra que el repertorio de protesta puede resultar limitado en una región donde se juegan tantos intereses políticos y económicos contrarios a los que representa Ascamcat, pero también pone en evidencia que el campesinado no está dispuesto a adoptar un rol pasivo en su desarrollo.

A mediano plazo el proceso de negociación y los acuerdos alcanzados se revelaron como un incumplimiento más de los compromisos adquiridos con el campesinado. En contraste, en enero de 2016 el gobierno sancionó la ley 1776 “Por la cual se crean y se desarrollan las Zonas de Interés de Desarrollo Rural, Económico y Social, Zidres”, cuyo trámite se retrotrae a 2014 y cuyo debate estuvo marcado por las denuncias de acumulación irregular de baldíos por grandes empresas agroindustriales y particulares. De acuerdo con Medina (2016, pp. 16-17), la ley continúa apostando por un modelo de desarrollo agrario fundado en la agroindustria, en donde los gremios empresariales son determinantes para la formulación de la política agraria. Se impuso claramente la voluntad del gobierno en contra de las demandas de las organizaciones campesinas e incluso en contravía de lo acordado en La Habana en materia agraria. La Ley hace depender la asignación de tierras de la capacidad financiera de la empresa productiva, lo que beneficia a los grandes empresarios nacionales y transnacionales sobre los campesinos y pequeños propietarios. Estos quedan a merced de los primeros, ya sea como trabajadores o como socios que asumen la mayoría de los riesgos de las empresas en el marco de las “alianzas productivas”, además de perder la posibilidad de decidir sobre los recursos naturales y la vida colectiva en sus territorios.

Por eso, en agosto de 2014, campesinos de 59 veredas en los municipios de Teorama y San Calixto, se declararon como ZRC de facto, exigiendo su reconocimiento legal. También seguían demandando soluciones para la crisis humanitaria producto de las confrontaciones entre la Fuerza de tarea Vulcano, las guerrillas y los paramilitares (Restrepo, 2015, p. 16).

\section{Referencias}

Ascamcat. (2012). Plan de desarrollo sostenible para la constitución de la zona de reserva campesina del Catatumbo. Bucaramanga: Ascamcat.

Ascamcat. (2013a). Metodología propuesta por los campesinos y campesinas para el funcionamiento de la Mesa de Interlocución y Acuerdo -MIA del Catatumbo. Recuperado de: http://prensarural.org/spip/spip.php? article11149 (25 de junio de 2013)

Ascamcat. (2013b). La movilización campesina se mantiene hasta que no se solucione la crisis del Catatumbo. Recuperado de: http://prensarural.org/spip/spip.php?article11237 (29 de junio de 2013).

Ascamcat. (2013c). Llamado a la movilización nacional de las organizaciones campesinas, indígenas, afrocolombianas y populares. Recuperado de: http://www.rebelion.org/noticia.php?id=170543\&titular=llamado-ala-movilizaci\%F3n-nacional-de-las-organizaciones-campesinas-ind\%EDgenas-afrocolombianas-y-populares- (2 de julio de 2013).

Ascamcat. (2013d). Pliego de exigencias del campesino movilizado en el Catatumbo. Recuperado de: http://www.marchapatriotica.org/index.php?option=com content\&view=article\&id=888:catatumbo-pliego-depeticiones\&catid=107\&Itemid=482 (15 de junio de 2013).

CINEP. (2014). Informe especial. Luchas sociales en Colombia 2013. Bogotá: CINEP.

Cruz, E. (2012). La MANE y el paro nacional universitario de 2011 en Colombia. Ciencia Política, 14, $140-193$.

Cruz, E. (2013). Todos somos hijos del café. Sociología política del paro nacional cafetero. Entramado, 9(2), 138158. 
Cruz, E. (2014). Dignidad en movimiento. El ascenso de la movilización social en Colombia. Confluenze. Revista di Studi Iberoamericani Universitá di Bologna, 6(25), 241-275.

Cruz, E. (2015). El derecho a la protesta social en Colombia. Pensamiento Jurídico, 42, 47-69.

Duque, H. (2013). Escollos en el Catatumbo. Recuperado de: http://prensarural.org/spip/spip.php?article12155 (20 de septiembre de 2013).

Logran acuerdo para desbloquear vías en Catatumbo (31 de julio de 2013). El Espectador. Recuperado de: http://www.elespectador.com/noticias/nacional/logran-acuerdo-desbloquear-vias-catatumbo-articulo-437266

Acuerdo social por el Catatumbo (31 de julio de 2013). El Espectador. . Recuperado de: http://www.elespectador.com/noticias/politica/acuerdo-social-el-catatumbo-articulo-437313

Campesinos abandonan vías tras 53 días de protestas en Catatumbo (3 de agosto de 2013). El Espectador. Recuperado de: http://www.elespectador.com/noticias/nacional/campesinos-abandonan-vias-tras-53-dias-deprotestas-cat-articulo-437875

Campesinos del Catatumbo rechazan señalamientos de infiltraciones guerrilleras (24 de junio de 2013). El Espectador. Recuperado de: http://www.elespectador.com/noticias/politica/campesinos-del-catatumbo-rechazansenalamientos-de-infi-articulo-429810

'Marchas en el Catatumbo están infiltradas por las Farc': Gobierno (20 de junio de 2013). El Tiempo.. Recuperado de: http://www.eltiempo.com/archivo/documento/CMS-12882977

En riesgo, cosecha de palma (25 de junio de 2013). El Tiempo. Recuperado de: http://www.eltiempo.com/archivo/documento/MAM-6275757

Campesinos del Catatumbo analizan plan presentado por el Gobierno (29 de junio de 2013). El Tiempo. Recuperado de: http://www.eltiempo.com/archivo/documento/CMS-12900602

Sigue paro en el Catatumbo, Gobierno y campesinos no llegan a acuerdos (29 de junio de 2013). El Tiempo. Recuperado de: http://www.eltiempo.com/archivo/documento/CMS-12900745

Lo que se juega en el Catatumbo (30 de junio de 2013). El Tiempo. Recuperado de: http://www.eltiempo.com/archivo/documento/CMS-12901160

Expectativa por cita con líderes del Catatumbo (2 de julio de 2013). El Tiempo. Recuperado de: http://www.eltiempo.com/archivo/documento/CMS-12904209

Campesinos del Catatumbo no aceptan propuesta para inicio de diálogos (7 de julio de 2013). El Tiempo. Recuperado de: http://www.eltiempo.com/archivo/documento/CMS-12915127

Gobierno autorizó comisiones de 'alto nivel' para crisis en Catatumbo (8 de julio de 2013). El Tiempo. Recuperado de: http://www.eltiempo.com/archivo/documento/CMS-12919347

Negociación en el Catatumbo sigue sin mayores avances (10 de julio de 2013). El Tiempo. Recuperado de: http://www.eltiempo.com/archivo/documento/CMS-12922466

Vicepresidente Garzón reunido con campesinos en Catatumbo (13 de julio de 2013). El Tiempo. Recuperado de: http://www.eltiempo.com/archivo/documento/CMS-12926863

Santos mantiene el no al diálogo en Catatumbo con bloqueos (27 de julio de 2013). El Tiempo. Recuperado de: http://www.eltiempo.com/archivo/documento/CMS-12951368

'Quieren incendiar el país y no lo vamos a permitir': Carrillo (7 de julio de 2013). El Tiempo. Recuperado de: http://www.eltiempo.com/archivo/documento/CMS-12915465 
Un geólogo estudiado en Europa, el vocero de campesinos del Catatumbo (4 de julio de 2013). El Tiempo. Recuperado de: http://www.eltiempo.com/archivo/documento/CMS-12908148

Manifestantes del Catatumbo solicitan refugio a Venezuela (22 de julio de 2013). El Tiempo. Recuperado de: http://www.eltiempo.com/archivo/documento/CMS-12941670

'Que no nos crean bobos con zona de reserva campesina de Catatumbo' (30 de julio de 2013). El Tiempo. Recuperado de: http://www.eltiempo.com/archivo/documento/CMS-12956862

Señalamientos de ONU sobre Catatumbo son 'temerarios e irresponsables' (11 de julio de 2013). El Tiempo. Recuperado de: http://www.eltiempo.com/archivo/documento/CMS-12924048

Se agudiza problema en el Catatumbo (22 de junio de 2013). El Tiempo. Recuperado de: http://www.eltiempo.com/archivo/documento/CMS-12888781

Estrada Álvarez, J. (2013). La producción campesina del territorio. Las zonas de reserva campesina. Espacio Crítico, 18, 24-33.

Fundación Ideas para la Paz -FIP-. (2013). Dinámicas del conflicto armado en el Catatumbo y su impacto humanitario. Bogotá: FIP. Recuperado de: http://archive.ideaspaz.org/images/REPORTE\%20DE \%20MONITOREO\%20CATATUMBO\%2019092013.pdf

León, J. (28 de junio de 2013). La otra versión sobre el Catatumbo. Recuperado de: http://lasillavacia.com/historia/la-otra-version-sobre-el-catatumbo-45125

300 campesinos del Catatumbo bloquean el cruce de carreteras en "La Aduana" (14 de junio de 2013). Marcha Patriótica. Recuperado de: http://www.marchapatriotica.org/index.php? option=com content\&view=article\&id=886:300-campesinos-del-catatumbo-bloquean-el-cruce-de-carreteras-en$\underline{\text { la-aduana\&catid=107\&Itemid }=482}$

Tensión en el Catatumbo (15 de junio de 2013). Marcha Patriótica. Recuperado de: http://www.marchapatriotica.org/index.php?option=com content\&view=article\&id=887:tension-en-elcatatumbo\&catid $=107 \&$ Itemid $=482$

Avanza el diálogo entre campesinos y gobierno en el Catatumbo (28 de junio de 2013). Marcha Patriótica. Recuperado de: http://www.marchapatriotica.org/index.php?option=com content\&view=article\&id=779:avanzael-dialogo-entre-campesinos-y-gobierno-en-el-catatumbo\&catid=107\&Itemid=482

Propuesta metodológica consensuada y actualizada por los campesinos movilizados del Catatumbo (28 de junio de 2013). Marcha Patriótica. Recuperado de: http://www.marchapatriotica.org/index.php? option=com content\&view=article\&id=777:propuesta-metodologica-consensuada-y-actualizada-por-loscampesinos-movilizados-del-catatumbo\&catid=107\&Itemid=482

Mensaje de buena voluntad del campesinado del Catatumbo al presidente Santos (30 de junio de 2013). Marcha Patriótica. Recuperado de: http://www.marchapatriotica.org/index.php? option=com content\&view=article\&id=789:mensaje-de-buena-voluntad-del-campesinado-del-catatumbo-alpresidente-santos $\&$ catid $=107 \&$ Itemid $=482$

Comunicado de las comisiones de paz del Congreso de la República sobre la situación en el Catatumbo (28 de junio de 2013). Marcha Patriótica. Recuperado de: http://www.marchapatriotica.org/index.php? option=com content\&view=article\&id=782: comunicado-de-las-comisiones-de-paz-del-congreso-de-la-republicasobre-la-situacion-en-el-catatumbo\&catid=107\&Itemid=482

McAdam, D. (1999). Orígenes terminológicos, problemas actuales, futuras líneas de investigación. En McAdam, D., McCarthy, J. y Zald., M. (ed.), Movimientos sociales: perspectivas comparadas. Oportunidades políticas, estructuras de movilización y marcos interpretativos culturales. Madrid: Itsmo. 
McAdam, D., McCarthy, J. y Zald, M. (1999). Movimientos sociales: perspectivas comparadas. Oportunidades políticas, estructuras de movilización y marcos interpretativos culturales. Madrid: Itsmo.

McAdam, D., Tarrow, S. y T. Ch. (2005). Dinámica de la contienda política. Barcelona: Hacer.

McCarthy, D. (1999). Adoptar, adaptar e inventar límites y oportunidades. En McAdam, D., McCarthy, J. y Zald, M. (eds.), Movimientos sociales: perspectivas comparadas. Oportunidades políticas, estructuras de movilización y marcos interpretativos culturales (pp. 205-220). Madrid, Itsmo.

Medina, J. (2016). Zidres: porfía y resistencia. Cien Días, 87, 16-19.

Molano Bravo, A. (2013). Dignidad campesina. Entre la realidad y la esperanza. Bogotá: Icono.

Peñaranda, D. (2011). Contra viento y marea. Acciones colectivas de alto riesgo en zonas rurales colombianas. Bogotá: Universidad Nacional de Colombia-La Carreta.

Pizarro, E. (2011). Las Farc 1949-2011. De la guerrilla campesina a la máquina de guerra. Bogotá: Norma.

PNUD. (2012). El campesinado colombiano. Reconocimiento para construir país. Bogotá: PNUD.

PNUD. (2014). Catatumbo. Análisis de Conflictividades y construcción de paz. Bogotá: PNUD

Exitoso encuentro de la Asociación Campesina del Catatumbo (14 de octubre de 2013). Prensa Rural. Recuperado de: http://www.prensarural.org/spip/spip.php?article77

Ascamcat aseguró que no ocasionó los destrozos en la Fiscalía de Tibú (14 de junio de 2013). Prensa Rural. Recuperado de: http://prensarural.org/spip/spip.php?article11086

1.200 campesinos del Catatumbo bloquean las vías Ocaña - Aguachica y Ocaña - Convención (18 de junio de 2013). Prensa Rural. Recuperado de: http://prensarural.org/spip/spip.php?article11125

Catatumbo resiste (Segunda Entrega) (18 de junio de 2013). Prensa Rural. Recuperado de: http://prensarural.org/spip/spip.php?article11129

Dos campesinos mueren por disparos en la protesta del Catatumbo (25 de junio de 2013). Prensa Rural. Recuperado de: http://prensarural.org/spip/spip.php?article11202

Estos son los verdaderos perfiles de los voceros de la movilización campesina del Catatumbo (4 de julio de 2013). Prensa Rural. Recuperado de: http://www.prensarural.org/spip/spip.php?article11276

De nuevo se enfrentan campesinos y Esmad en el Catatumbo (12 de julio de 2013). Prensa Rural. Recuperado de: http://prensarural.org/spip/spip.php?article11349

Comunidades académicas manifiestan solidaridad con el campesinado del Catatumbo (16 de junio de 2013). Prensa Rural. Recuperado de: http://www.prensarural.org/spip/spip.php?article11113

El Ejército asesinó en Ocaña a dos campesinos del Catatumbo. Además 10 heridos por bala de fusil. Prensa Rural. Recuperado de: http://www.prensarural.org/spip/spip.php?article11165

Campesinos del Catatumbo piden hablar con Santos (26 de julio de 2013). Prensa Rural. Recuperado de: http://www.prensarural.org/spip/spip.php?article11489

No se produjo la reunión entre los campesinos del Catatumbo y el Ministro de Agricultura (15 de junio de 2013). Prensa Rural. Recuperado de: http://www.prensarural.org/spip/spip.php?article11094

Catatumbo resiste (Primera Entrega). (16 de junio de 2013). Prensa Rural. Recuperado de: http://www.prensarural.org/spip/spip.php?article11110 
Catatumbo resiste (Tercera Entrega). (18 de junio de 2013). Prensa Rural. Recuperado de: http://www.prensarural.org/spip/spip.php?article11130

Ramírez Tobón, W. (1990). Estado, violencia y democracia. Bogotá: Universidad Nacional de Colombia-Tercer Mundo.

Ramírez, M. (2001). Entre el Estado y la guerrilla: identidad y ciudadanía en el movimiento de los campesinos cocaleros del Putumayo. Bogotá: ICANH.

Continúa la movilización en el Catatumbo: siete mil campesinos apoyan la protesta (21 de junio de 2013 ). Rebelión. Recuperado de: http://www.rebelion.org/noticia.php?id=170086\&titular=contin\%FAa-la-movilizaci \%F3n-en-el-catatumbo:-siete-mil-campesinos-apoyan-la-protesta-

Carta al Ministro de Agricultura sobre la crisis en el Catatumbo (18 de junio de 2013). Rebelión. Recuperado de: http://www.rebelion.org/noticia.php?id=169862\&titular=carta-al-ministro-de-agricultura-sobre-la-crisis-en-elcatatumbo-

Restrepo, A. (2013). Protestas en el Catatumbo: ¿y la historia?. Cien Días, 79, 17-20.

Restrepo, A. (2015). Del paro a la mesa y de la mesa al paro. El Ejecutivo nacional frente al movimiento campesino. Cien Días, 84, 15-18.

Restrepo, J. (24 de marzo de 2013). Republiquetas, no; zonas de reserva campesina, sí. Recuperado de: http://www.eltiempo.com/archivo/documento/CMS-12709742

Rivas, A. (1998). El análisis de los marcos: una metodología para el estudio de los movimientos sociales. En Ibarra, P. y Tejerina, B. (eds.), Los movimientos sociales. Transformaciones políticas y cambio cultural (pp. 181215). Madrid: Trotta.

Salinas Abdala, Y. (7 de julio de 2013). ¿Arde el Catatumbo?: respuesta inadecuada a una protesta legítima. Recuperado de: http:/www.razonpublica.com/index.php/conflicto-drogas-y-paz-temas-30/6945-iarde-elcatatumbo-respuesta-inadecuada-a-una-protesta-legitima.html?highlight=WyJwYXJvIiwiY2F0YXR1bWJvIl0=

Reportaje: por qué arde el Catatumbo (22 de junio de 2013). Semana. Recuperado de: http://www.semana.com/nacion/articulo/reportaje-que-arde-catatumbo/348448-3

Tibú: el desplante de los campesinos al Gobierno (19 de junio de 2013). Semana. Recuperado de: http://www.semana.com/nacion/articulo/tibu-desplante-campesinos-gobierno/348175-3

Los campesinos de Tibú dejan plantado al Gobierno (19 de junio de 2013). Semana. Recuperado de: http://www.semana.com/nacion/articulo/los-campesinos-tibu-dejan-plantado-gobierno/348213-3

La condición del Gobierno para dialogar con campesinos (24 de junio de 2013). Semana. Recuperado de: http://www.semana.com/nacion/articulo/la-condicion-del-gobierno-para-dialogar-campesinos/348698-3

Garzón no puso punto final al paro en Catatumbo (15 de julio de 2013). Semana. Recuperado de: http://www.semana.com/nacion/articulo/garzon-no-puso-punto-final-paro-catatumbo/350970-3

El acuerdo para poner fin al bloqueo del Catatumbo (31 de julio de 2013). Semana. Recuperado de: http://www.semana.com/nacion/articulo/el-acuerdo-para-poner-fin-bloqueo-del-catatumbo/352680-3

ONU pide investigar las muertes en Catatumbo (10 de julio de 2013). Semana. Recuperado de: http://www.semana.com/nacion/articulo/onu-pide-investigar-muertes-catatumbo/350307-3

Protestas en el Catatumbo son justas (2013). Semana. Recuperado de: http://www.semana.com/nacion/articulo/protestas-catatumbo-justas/351752-3 
Snow, D. \& Benford, R. (1992). Master frames and cycles of protest. En Morris, A. \& McClury, C. (eds.), Frontiers in social movement theory (pp. 133-155). New Haven and London: Yale University Press.

Suhner, S. (2002). Resistiendo al olvido. Tendencias recientes del movimiento social y de las organizaciones campesinas en Colombia. Bogotá: Taurus UNRISD.

Tarrow, S. (1997). El poder en movimiento. Los movimientos sociales, la acción colectiva y la política. Madrid: Alianza.

Vargas, V. (13 de julio de 2013). Protesta social en el Catatumbo geoestratégico. Recuperado de: http://prensarural.org/spip/spip.php?article11354.

Vega, R. y Aguilera, M. (1995). Obreros, colonos y motilones. Una historia social de la concesión Barco 19301960. Bogotá: Fedepetrol-CISF.

Zald, M. (1999). Cultura, ideología y creación de marcos estratégicos. En McAdam, D. McCarthy, J. y Zald, M. (eds), Movimientos sociales: perspectivas comparadas. Oportunidades políticas, estructuras de movilización y marcos interpretativos culturales (pp. 369-388). Madrid: Itsmo. 